\title{
STAND-LEVEL HERBIVORY IN AN OLD-GROWTH CONIFER FOREST CANOPY
}

\author{
David C. Shaw ${ }^{1,2}$, Kristina A. Ernest ${ }^{3}$, H. Bruce Rinker ${ }^{4}$, Margaret D. Lowman ${ }^{5}$
}

\begin{abstract}
Herbivory is an important ecological process in forest canopies but is difficult to measure, especially for whole stands. We used the Wind River Canopy Crane in Washington State to access 101 randomly-located sample points throughout the forest canopy. This provided a relatively quick and convenient way to estimate herbivory for a whole stand. The overall level of herbivory was estimated at $1.6 \%$ of leaf area. The distribution was strongly skewed to the lower canopy where broad-leafed species experienced higher levels of herbivory. Herbivory averaged $0.3 \%$ in conifers and $13.5 \%$ in broad-leafed species. Fully half of the sample points had no detectable herbivory. Herbivory in this old-growth conifer forest is among the lowest levels published for forests around the globe and may reflect the general levels of herbivory in temperate coniferous forests during nonoutbreak conditions. Our whole-stand estimate is the first attempt at measuring herbivory for an entire forest stand in the Pacific Northwest.
\end{abstract}

Key words: herbivory, old-growth, conifers, Wind River Canopy Crane.

The forest canopy plays an important role in biodiversity, ecophysiology, productivity, and function of forest ecosystems (Ozanne et al. 2003, Lowman and Rinker 2004). Within forest canopies, herbivory as an ecological process influences net primary productivity, nutrient cycling, and forest trophic interactions (Schowalter et al. 1986, Lowman 1995, McNaughton 2001, Rinker and Lowman 2004). Various invertebrates and vertebrates consume plant tissues, but arthropods are considered the most significant foliage herbivores in forest trees (Lowman 1995, Rinker and Lowman 2004). Levels of herbivory in whole forests or stands are rarely measured, yet information on herbivory is fundamental to understanding forest productivity, turnover, and health.

In conifer-dominated forests of the Pacific Northwest, most data on stand-level herbivory come from defoliation events during insect outbreaks. Defoliation is an extreme level of herbivory in which the crown of a tree is visibly missing most foliage. When insect outbreaks occur, investigators often estimate the total area (e.g., acres) of forest affected rather than quantifying the percent of foliage (leaf area) removed. For example, the western spruce budworm defoliated 139,900 acres in Washington State in 2003 (USDA Forest Service 2004). Sometimes defoliation is described as the proportion of individual trees per unit area that are defoliated; catagories are typically used. For example, areas that experienced outbreaks of Douglas-fir tussock moth and western spruce budworm have been described categorically as $50 \%-75 \%$ or $75 \%-100 \%$ defoliated (Brubaker and Greene 1979).

Herbivory in forest trees of the Pacific Northwest in nonoutbreak conditions has been reported only 3 times. Schowalter and Ganio (1998) used a discrete branch-level sampling technique to quantify herbivory in a single old-growth forest stand at Wind River, WA. They clipped branches and visually estimated the percent leaf area missing at the branch scale. Herbivory in canopy trees was $<2 \%$ for Douglas-fir, $<1 \%$ for grand fir, $0 \%$ for western hemlock, and $<1 \%$ for western red cedar. Using this same method across several sites at the H.J. Andrews Experimental Forest in Oregon, Schowalter (1995) reported that herbivory for mature Douglas-fir was $3.7 \%$ (range $0 \%-11 \%)$, while herbivory for old-growth Douglas-fir was $1.9 \%$ (range 0\%-6\%). In another study, Schowalter (1989) estimated that herbivory was $<1 \%$ in old-growth Douglas-fir trees at several sites in western Oregon.

\footnotetext{
${ }^{1}$ Wind River Canopy Crane Research Facility, University of Washington, 1262 Hemlock Road, Carson, WA 98610.

${ }^{2}$ Present address: Department of Forest Science, Oregon State University, Corvallis, OR 97331. Email: dave.shaw@oregonstate.edu

${ }^{3}$ Department of Biological Sciences, Central Washington University, Ellensburg, WA 98926.

${ }_{4}^{4}$ Pinellas County Environmental Lands Division, Environmental Lands Division, 3620 Fletch Haven Drive, Tarpon Springs, FL 34688.

${ }^{5}$ New College of Florida, Sarasota, FL 34243.
} 
Perhaps a partial explanation for the paucity of data on herbivory for whole forests is the difficulty imposed by adequately sampling variability in herbivory within a forest. Indirect methods, such as estimating consumption from insect frass production, require potentially unrealistic assumptions, and herbivory estimates from litter traps incorporate biases inherent in litter fall. Direct estimates of herbivory from intact leaves are less biased but appear to require complex sampling procedures. Lowman (1995) proposed a protocol that uses replicated sampling of individual leaves, branch systems, crown zones, trees, and forest stands, which is then scaled up to the forest level. The amount of subsampling required is daunting. At our study site in the Pacific Northwest, for example, 65 species of vascular plants $(8$ conifers, 13 shrubs, 41 herbs, and 3 graminoids) occur in a 4-ha plot (Shaw et al. 2004). In addition, the forest trees include understory, intermediate, codominant, and dominant height classes, leaves in various age classes up to 8 years old, and a variety of light and shade conditions. Because light environment, leaf age, and height within individual tree crowns are known to affect herbivory (Coley 1983, Lowman 1985), the scaling exercise would require replicating patterns such as sun and shade environments on the forest floor, vertical heights or strata within crowns, various size classes (ages) of trees, and different leaf ages. Access to the full vertical dimensions of trees that are unsafe to climb also poses logistic problems. Techniques that are more time-efficient must be developed (Lowman 1995).

Another reason for the scarcity of data on stand-level herbivory in the Pacific Northwest may be that sampling herbivory on coniferous needle-leafed trees is more challenging than on broad-leafed plants. Coniferous needles pose many problems for estimating herbivory because they are numerous, small, and difficult to label. Once the needle is removed by an herbivore, the petiole may be hard to see; therefore, the complete consumption of a needle may be missed. Broad-leafed species have fewer and larger leaves, making estimates easier; and petioles may be larger and easier to detect when the leaf has been eaten. An old-growth Douglas-fir tree can have over 1 million leaves (Franklin et al. 1981). Sampling 1\% of these leaves in a systematic way, across all age classes and light regimes, is a formidable task.
The purpose of this study was to estimate stand-level herbivory, including the understory, for a Pacific Northwest coniferous forest stand. We employed an alternative method of estimating herbivory (Ernest et al. unpublished manuscript)—by sampling percent leaf area consumed at random locations within the canopy - to eliminate the need for the intensive sampling required for scaling-up, as described previously. A canopy crane provided access to the entire volume of the canopy of the forest stand we investigated. We compare our estimates of stand-level herbivory with those from other methods and forests and suggest how measures of stand-level herbivory are important in understanding broader forest processes.

\section{Methods}

Study Site

Our study site was located at the Wind River Canopy Crane Research Facility (WRC$\mathrm{CRF}$ ) in a 500-year-old coniferous forest in the Cascade mountains of southwestern Washington State (Shaw and Greene 2003, Shaw et al. 2004). Elevation was $371 \mathrm{~m}$ on a $<10 \%$ slope. Average annual temperature was $8.7^{\circ} \mathrm{C}$, and average annual precipitation was 2223 mm. Soils were medial, mesic Entic Vitrands that are deep (2-3 m) and included welldrained loams and silt loams. The vegetation was transitional across 2 major plant association types: the western hemlock zone and Pacific silver fir zone. Dominant trees included Douglas-fir (Pseudotsuga menziesii; 35 trees . $\mathrm{ha}^{-1}$ ), western hemlock (Tsuga heterophylla; 224 trees $\cdot$ ha $^{-1}$ ), Pacific yew (Taxus brevifolia; 86 trees $\left.\cdot \mathrm{ha}^{-1}\right)$, and western red cedar (Thuja plicata; 30 trees $\left.\cdot \mathrm{ha}^{-1}\right)$. Stand density was 427 trees $\cdot \mathrm{ha}^{-1}$ and basal area was $82.9 \mathrm{~m}^{2} \cdot \mathrm{ha}^{-1}$. The understory was dominated by vine maple (Acer circinatum), salal (Gaultheria shallon), and Oregon grape (Berberis aquifolium) and was generally classified as the western hemlock / salal plant association complex (Shaw et al. 2004). Common regenerating conifers in the understory included western hemlock and Pacific silver fir (Abies amabalis). Total stand leaf area index (LAI) was estimated at 8.6, and LAI for the understory vegetation was 1.7 (Thomas and Winner 2000). 


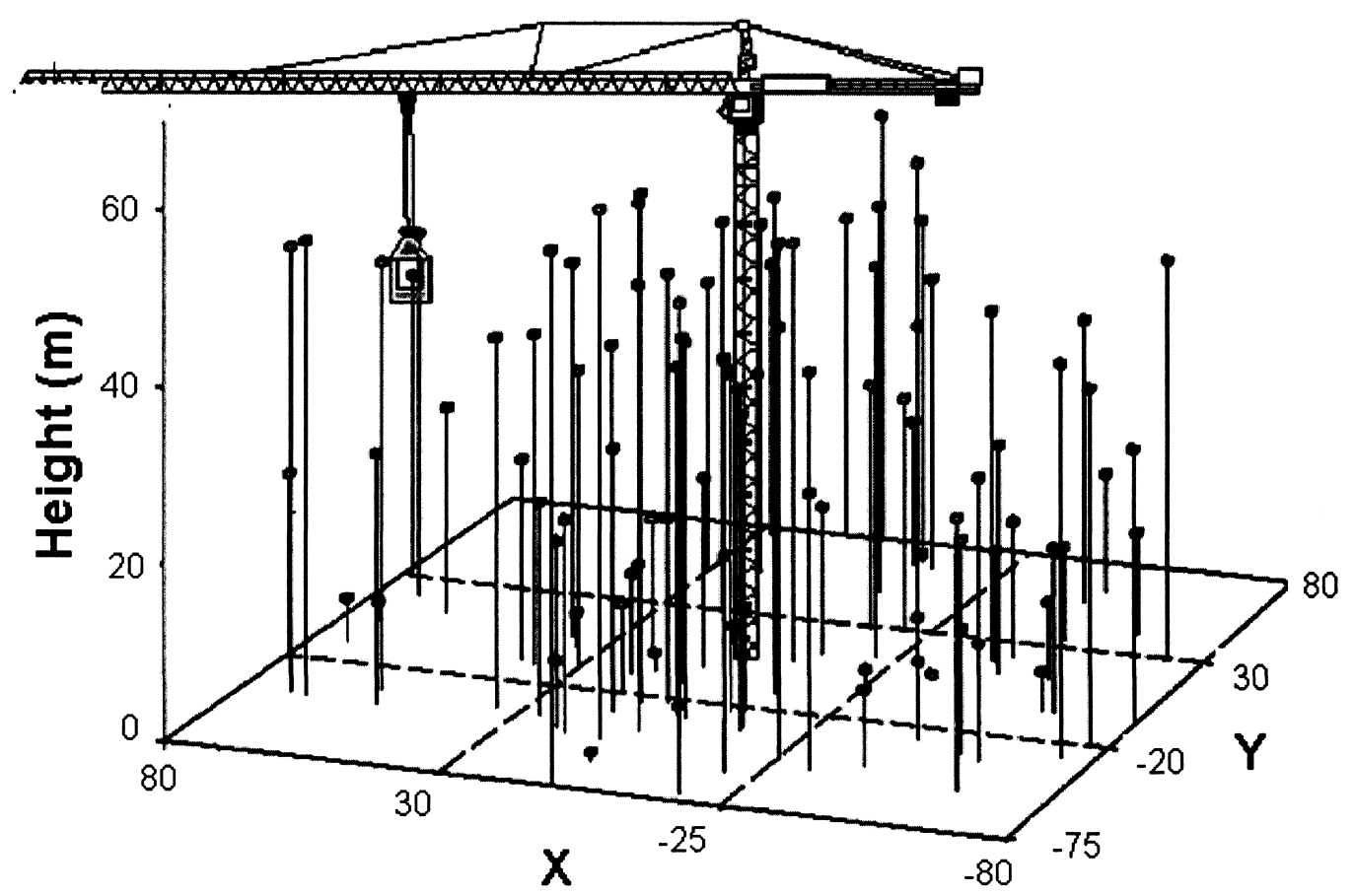

Fig. 1. Spatial distribution of all 101 sample locations plots under the canopy crane. Reprinted from Lowman and Rinker (2004:365), with permission from Elsevier.

\section{Canopy Crane}

Canopy cranes are a relatively new tool for the study of forest canopies (Mitchell et al. 2002, Basset et al. 2003). A tower crane, standard to construction sites of tall buildings, consists of a tower with a jib positioned at the top. In forest canopy studies, the tower is taller than the surrounding vegetation and the jib can swing in a $360^{\circ}$ arc over the trees. A gondola attached to the hook carries scientists and is lowered into place from above the tree tops. This provides access to the 3-dimensions of forest canopies under the swing of the jib. The jib of the Wind River Canopy Crane covers 2.3 ha of forest (85-m radius).

\section{General Herbivory Protocol}

To ensure that we would actually be able to estimate herbivory in about 100 locations, we used Microsoft Excel to generate a list of 200 random $x, y, z$ points from within the circle of the canopy crane. We divided the list of 200 points into 4 subsets to minimize time spent moving the gondola around the forest while simultaneously ensuring that sample points were located throughout the forest. We went to each location in order, starting with the first subset. If the $x, y, z$ random point was not accessible (due to obstruction by branches), too close to the tower (where foliage had been removed or was disturbed), or in midair $>5 \mathrm{~m}$ from any foliage, the point was skipped. We actually estimated herbivory in 101 sample locations (Fig. 1) and included leaves from any vascular plant species present. We did not measure herbivory on lichens or mosses.

\section{Plot Frame, Subplot \\ Frame, Leaf Units}

To choose leaves in an unbiased manner at each $\mathrm{x}, \mathrm{y}, \mathrm{z}$ gondola location, we selected leaves (or leaf units) from a randomly chosen subplot within a plot as follows. We held a $50 \mathrm{~cm} \times 50$ $\mathrm{cm} \times 50-\mathrm{cm}$ plot frame against the railing of the gondola. This created eight $25 \mathrm{~cm} \times 25 \mathrm{~cm}$ $\times 25$-cm subplots within the plot frame. We randomly chose a number between 1 and 8 and used a subplot frame $(25 \mathrm{~cm} \times 25 \mathrm{~cm} \times 25 \mathrm{~cm}$; Fig. 2) to delineate the space within which we would select leaves. 


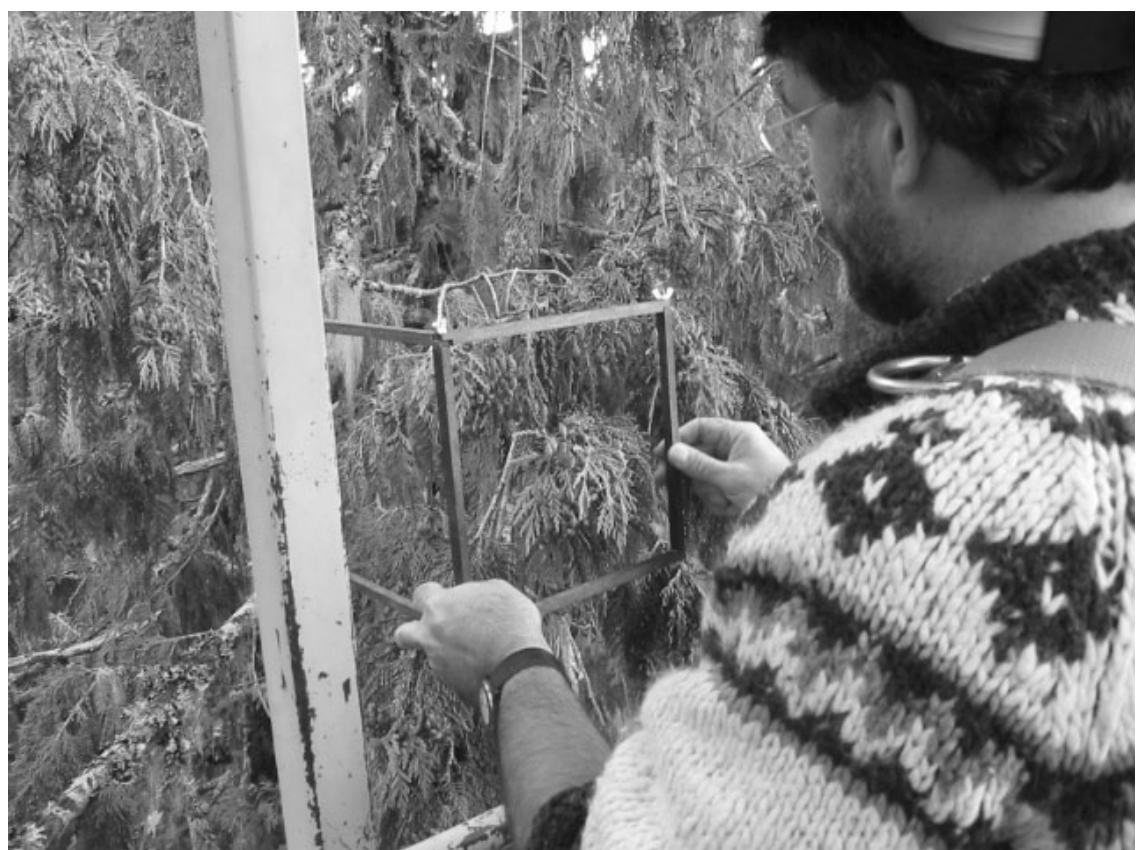

Fig. 2. Subplot frame $(25 \mathrm{~cm} \times 25 \mathrm{~cm} \times 25 \mathrm{~cm})$ used for selecting sample foliage. For the scale-leafed western red cedar, the length $(\mathrm{S})$ of foliated stems was divided by 10 and then 10 fronds were selected, each $\mathrm{S} / 10 \mathrm{~cm}$ apart along stems.

Within the subplot frame we randomly selected 10 leaves (or leaf units), regardless of plant species. The selection process varied for broad-leafed species, scale-leafed conifers, and needle-leafed conifers due to their different leaf sizes and arrangements. For broad-leafed species we counted the total number of leaves (L) within the subplot and divided by 10 . We estimated herbivory on every L/10th leaf (10 leaves sampled per sample location). For example, if there were 30 leaves in the subplot, $30 / 10=3$, so every 3rd leaf was sampled. For all conifers, we measured the total length of stems ( $\mathrm{S}$; excluding sections without needles) within the subplot and divided by 10 . For scaleleafed conifers (western red cedar), fronds constituted leaf units (Edelstein and Ford 2003). We selected 10 fronds, each $\mathrm{S} / 10 \mathrm{~cm}$ apart along the stems, and estimated herbivory for the entire frond. Because leaves of needleleafed species are so small, we defined the leaf unit as 5 adjacent leaves along the stem. We selected 10 leaf units, each $\mathrm{S} / 10 \mathrm{~cm}$ apart along the stems, and estimated herbivory for each of these needles $(5$ leaves $\times 10$ leaf units $=50$ leaves per sample location).

\section{Estimating Herbivory}

Herbivory for the entire forest stand was estimated by first averaging the leaf units within each sample location and then averaging among the 101 sample locations.

\section{RESULTS}

\section{Herbivory Estimate}

Most herbivory in this forest canopy was caused by insects. We observed partial (holes chewed through tissue) and complete leaf consumption (petiole still present but leaf blade absent). Average herbivory at individual sample locations ranged from $0 \%$ to $73 \%$. Fiftyone locations $(50 \%)$ had no detectable herbivory; 32 locations $(32 \%)$ had between $0 \%$ and $1 \%$ herbivory; 14 locations (14\%) had between $1 \%$ and $10 \%$ herbivory; and 4 locations $(4 \%)$ had $>10 \%$ herbivory (Fig. 3). Although 73\% was the highest estimate for a single location, the next highest estimate was $16 \%$. Average total discrete herbivory in this old-growth conifer forest (101 sample locations) was estimated at $1.6 \%$ of leaf area. 


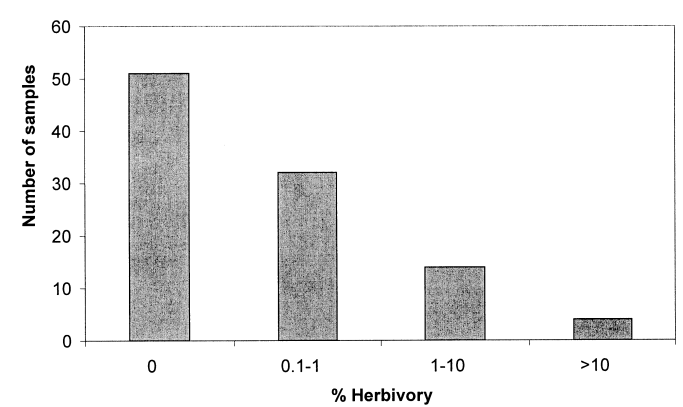

Fig. 3. Frequency distribution of herbivory levels at 101 sample locations randomly located throughout the canopy.

All sample locations with broad-leafed species had detectable herbivory (frequency $100 \%$ ), while only $44 \%$ of sample locations with conifer species had any measurable herbivory. Herbivory averaged $0.3 \%$ (range $0 \%-4.9 \%$ ) for conifers (91 sample locations). Herbivory in conifer species ranged from $0.1 \%$ in western red cedar to $0.8 \%$ in Pacific yew (Table 1). Despite low average herbivory levels, the frequency of herbivory in conifers was relatively high, varying from $18 \%$ of sample locations in western red cedar to $40 \%$ in western hemlock, $46 \%$ in Douglas-fir, 67\% in Pacific yew, and $100 \%$ in grand fir. All estimates above $10 \%$ (for a sample location) were for broad-leafed species, which averaged $13.5 \%$ herbivory $(n=$ 10; Table 1). The highest herbivory estimates were in the lower canopy (Fig. 4). The distribution of herbivory by light zones (Parker 1997) also reflects this (Table 2). The transition and bright zones had exclusively conifer foliage, except for western hemlock dwarf mistletoe (Arceuthobium tsugense) aerial shoots. Western hemlock dwarf mistletoe occurred at only 1 sample location and did not have detectable herbivory.

\section{Discussion}

Our herbivory estimate, $1.6 \%$ of leaf area absent, is the first quantified estimate for an entire forest stand, including understory, in the Pacific Northwest. Our estimates for individual conifer tree species, all $<1 \%$, are similar to the few other estimates for old-growth forest trees (<2\%; Schowalter 1989, 1995, Schowalter and Ganio 1998).

Studies of forests around the world report a wide range of herbivory estimates (Landsberg and Ohmart 1989, Lowman 1995, Rinker and Lowman 2004). One reason is methodological. Point-in-time or discrete estimates (such as we used) require only a static measure of the total area or percent of area missing or damaged due to herbivory. Annual or long-term estimates (Lowman 1984) require the leaf to be labeled and resampled periodically over timeusually through 1 growing season or year. These dynamic measurements provide an estimate of actual rates of herbivory (\% leaf area consumed per time unit). Long-term rates are typically several times greater than discrete estimates because the latter often fail to detect (and thus to include) leaves that are completely consumed. For example, at several sites in the rainforests of Australia, annual rates of herbivory were 5 times greater than the discrete estimates (Lowman 1984). Long-term rates probably provide more accurate estimates of herbivory in relation to the impact on net primary production (Landsberg and Ohmart 1989) but may overestimate the impact of herbivory because of the difficulty in determining whether entirely missing leaves were consumed or removed by mechanical damage. Discrete herbivory estimates are still important for comparative purposes because most herbivory is estimated this way. In addition, long-term datasets on forest productivity, growth, and mortality benefit from some estimate of herbivory because this provides a context for the impact of herbivores. Currently, efforts are under way to determine whether discrete estimates of herbivory may be scaled to annual estimates (Lowman unpublished data).

In various reviews of forests across the globe (Landsberg and Ohmart 1989, Lowman 1995, Rinker and Lowman 2004), discrete herbivory for most forest trees ranges from approximately $5 \%$ to $15 \%$. Herbivory on temperate deciduous forest trees in North America ranges from $1 \%$ to $10 \%$, and in Europe ranges from $7 \%-10 \%$. Herbivory in tropical forests ranges from $8 \%$ (discrete) to $30 \%$ (long-term). In contrast, means of long-term herbivory for Australian sclerophyll forests range up to $300 \%$ per year. These data represent forest trees and do not include nontree understory vegetation. Our discrete estimates were $<1 \%$ for all tree species (excluding understory vegetation).

Comparing herbivory across sites has proven difficult because of the multiple methods used in sampling trees and forest stands. However, 
TABLE 1. Average herbivory levels for broad-leafed species, all conifers, dominant conifers, and all vascular plant species combined $(n=$ number of sample locations; average \% herbivory = percent of leaf area consumed by herbivores averaged among sample locations; $s_{\bar{x}}=$ standard error; range $=$ range of percent herbivory at individual sample locations; frequency $=$ percent of sample locations with any detectable herbivory).

\begin{tabular}{lrcccr}
\hline Plant species & $n$ & \% herbivory $(\bar{x})$ & $s_{\bar{x}}$ & Range & Frequency \\
\hline All broad-leafed species & 10 & 13.5 & 145.4 & $0-72.8$ & 100 \\
All conifers & 91 & 0.3 & 0.33 & $0-4.9$ & 44 \\
$\quad$ Abies grandis & 5 & 0.1 & 0.01 & $0-0.1$ & 100 \\
$\quad$ Pseudotsuga menziesii & 26 & 0.4 & 0.15 & $0-3.7$ & 46 \\
Taxus brevifolia & 6 & 0.8 & 0.78 & $0-3.5$ & 67 \\
Thuja plicata & 11 & 0.1 & 0.01 & $0-0.4$ & 18 \\
$\quad$ Tsuga heterophylla & 43 & 0.3 & 0.13 & $0-4.9$ & 40 \\
All vascular species & 101 & 1.6 & 5.7 & $0-72.8$ & 50 \\
\hline
\end{tabular}

TABLE 2. Average percent herbivory by light zone (sensu Parker 1997; $n=$ number of sample locations, frequency $=$ percent of sample locations with any detectable herbivory).

\begin{tabular}{lcccc}
\hline Zone & Height $(\mathrm{m})$ & $n$ & \% herbivory $(\bar{x})$ & Frequency \\
\hline Dim & $0-12$ & 25 & 5.64 & 68 \\
Transition & $12.1-40$ & 48 & 0.33 & 44 \\
Bright & $40.1+$ & 28 & 0.19 & 43 \\
\hline
\end{tabular}

for sites with access to the 3-dimensions of the canopy, we feel that a random sample technique, such as we describe here, is best suited for comparison of stand-level herbivory estimates around the globe. The International Canopy Crane Network (Basset et al. 2003) is a good starting point for global comparisons, and we used this technique at the Australian Canopy Crane near Cairns. Our method provides estimates, both in the data presented here and in our Australian data (8.6\% herbivory; Rinker et al. unpublished data), that are similar to estimates (from similar forest types) from other methods and has the advantage of being a relatively quick and convenient way to estimate total stand herbivory. It avoids the sampling bias inherent in most studies of forest herbivory, in which investigators have selectively chosen a subset of plant species (mostly trees) to sample. Our method is easily standardized across forest types and self-stratifies to the vertical height distribution of foliage in the forest (Ernest et al. unpublished data) so that differences in species composition, forest structure, and plant morphology can be accommodated without explicit experimental planning. Climbing techniques and other access systems have advanced to the point that canopy cranes are no longer necessary to sample the entire 3-dimensions of the forest canopy (Mitchell et al. 2002, Lowman and
Rinker 2004), and we anticipate our method can be adapted for use with these other forest access systems. We recognize that this method may not be applicable for estimating herbivory for specific species within a forest or for other investigations, but it does provide a more rapid assessment of stand-level herbivory.

From the limited data available, it appears that nonoutbreak temperate coniferous forests may have the lowest levels of herbivory in the world. Additionally, old-growth forests may have lower herbivory than younger forests (Schowalter 1989, 1995). Why is herbivory so low in these conifer forests? There is a general absence of orthopteran and coleopteran defoliators in Pacific Northwest coniferous forests; Lepidopterans are considered the primary defoliators. The low rate of herbivory in this stand may be related to low abundance of lepidopteran defoliators in the crowns of these coniferous trees. In a study of vertical and seasonal variation in arthropod communities in conifer tree crowns at the Wind River oldgrowth forest, lepidopteran defoliators were rare, while sap-sucking insects, predators, and detritivores were diverse and abundant (Schowalter and Ganio 1998). The complex structure and diversity of tree species in old-growth forests may maintain predator diversity and impede the ability of herbivores to discover suitable hosts and complete their development 


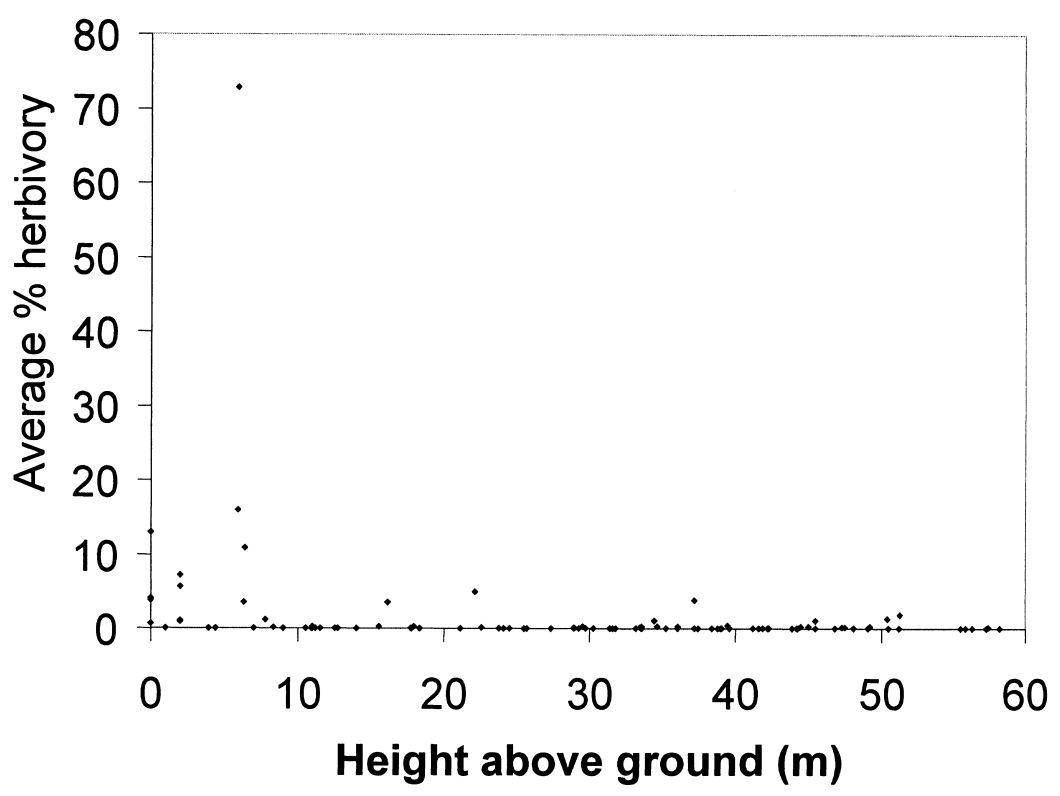

Fig. 4. Average percent discrete herbivory (per sample point) for 101 sample plots as a function of height above ground.

(Schowalter 1989). Experimental evidence shows that increasing the structural complexity of Douglas-fir branches increases spider diversity and abundance (Halaj et al. 2000). Birds are also important predators of arthropod defoliators, and insectivores dominate the bird community at Wind River (Shaw et al. 2002).

Additional evidence that natural enemies keep herbivore abundance low comes from comparative studies of Douglas-fir subspecies. Foliage from trees of eastern Oregon, where defoliator outbreaks of the western spruce budworm (Choristoneura occidentalis) occur periodically, caused a wide range of mortality in insect larvae, from limited amounts to $100 \%$ (Perry and Pitman 1983). Foliage from trees of western Oregon, where spruce budworm outbreaks are rare, caused little or no mortality of larvae. Perry and Pitman concluded that in western Oregon defoliation is limited by some factor other than host tree defenses and that predators and parasites may act to maintain budworm populations at relatively low levels.

Higher levels of herbivory and higher herbivore abundances were found in the understory. At our study site, highest herbivory is on the broad-leafed species in the understory
(13.5\%). Our discrete estimate for vine maple was $33 \%$ ( $n=3,30$ leaves). A separate study estimated the annual rate of herbivory on vine maple at Wind River (and 2 other old-growth stands) to be $9.9 \%$ ( $n=3,450$ leaves; Braun et al. 2002). The folivore community was exclusively lepidopteran caterpillars, dominated by 8 taxa that occurred sequentially through the season, but peaked in spring and early summer when foliage is presumably more palatable. This suggests that lepidopteran herbivores are abundant in the understory. In contrast, lepidopterans are not common on conifers (Schowalter and Ganio 1998). The difference may be related to the higher palatability of broadleafed versus conifer foliage, or some other factor such as predator distribution in the canopy. Fungal endophytes, which may be antagonistic to herbivores feeding on conifer foliage (Carroll 1991), could be a factor if fungal endophytes are uncommon in understory species. Regardless of the mechanism promoting higher herbivory in the understory than in the canopy, the pattern demonstrated here emphasizes the importance of quantifying herbivory both in the understory and in the canopy. Most estimates of forest-level herbivory from around the world are derived from 
canopy data alone. The understory, despite its lower biomass, may be critically important in driving forest processes such as tree regeneration, decomposition, and nutrient cycling in boreal forests (Nilsson and Wardle 2005). Our result showing more than 10-fold higher herbivory in the understory than in the canopy supports this notion for the temperate conifer forest.

Herbivory provides a context for other ecosystem processes and measures. For example, the gross primary productivity (GPP) at the WRCCRF site has been estimated (from 1999 data) at $1906 \mathrm{~g} \mathrm{C} \cdot \mathrm{m}^{-2} \mathrm{y}^{-1}$ (Harmon et al. 2004). The discrete estimate of herbivory does not represent an annual estimate but could be considered a conservative estimate for an annual rate. An estimate of the impact of herbivory on gross primary productivity at this site is at least $30.5 \mathrm{~g} \mathrm{C} \cdot \mathrm{m}^{-2} \mathrm{y}^{-1}$ (1.6\% of 1906). The leaf area index (LAI) of the site has been estimated at $8.6\left(\mathrm{~m}^{2} \cdot \mathrm{m}^{-2}\right.$; Thomas and Winner 2000). We estimate that herbivores remove at least $1.6 \%$ of this, which could lower the LAI to 8.5. Thomas and Winner (2000) also estimated understory LAI at 1.7, and we estimated that at least $5.6 \%$ of this was removed by herbivores, which could lower understory LAI to 1.6. Finally, the site is considered a sink for carbon dioxide based on eddy covariance data (Field and Kaduk 2004, Harmon et al. 2004, Paw U et al. 2004). The yearly source/sink status varies significantly depending on climatic patterns, and the effect of herbivory could influence whether the site is a source or a sink in certain years.

We acknowledge several limitations to this study. It represents only 1 forest stand $(n=1)$. Although the data are supported by several other studies, we should be cautious in using them to describe old-growth forest herbivory in general. Rather their usefulness lies in generating hypotheses and questions regarding herbivory in old-growth forests. Our estimation of discrete herbivory may largely miss mammalian herbivory in the canopy. For example, D. Shaw (personal observation) has routinely observed branchlet clipping by the Douglas squirrel (Tamiasciurus douglasii) during autumn, which our technique would not measure due to the focus on existing branches. Also, if an insect consumed the entire leaf including the petiole, or if the petiole fell off after leaf consumption, we would most likely not detect that herbivory. In addition, Schowalter (1995) found that bud moths reduced productivity by $13 \%$, but actual consumption was low. Our methods would miss this type of herbivory also.

A number of testable hypotheses arise from this study. (1) Lepidopteran folivores are more successful in the understory than in the overstory of old-growth forests due to the more palatable foliage on nonconiferous hosts in the understory. (2) Predatory arthropods and birds are more abundant in the crowns of coniferous trees than in the understory. (3) Long-term measurement of herbivory, including tagged leaves and branches, would result in higher herbivory estimates. And (4) estimates of herbivory based on leaf-level measurements underestimate true levels of foliage removal because activities such as branch clipping by squirrels and bud mining by caterpillars are not easily detected. We hope that future studies will test these hypotheses.

In summary, estimates of insect herbivory in forest ecosystems have been historically difficult to obtain due to challenges of access, spatial scales, and anecdotal methodologies. We provide an estimate for an old-growth conifer forest in the Pacific Northwest (1.6\%) based on random sampling in 3-dimensional canopy space. Although our estimate was a discrete (static) measure, employing this technique over the long term for intersite comparisons will undoubtedly allow us to establish dependable baseline information about links between herbivory and forest health.

\section{ACKNOWLEDGMENTS}

This research was supported by the Global Canopy Programme (John Krebs Field Station, Wytham, Oxford, U.K.), the Wind River Canopy Crane Research Facility (a cooperative scientific program of the University of Washington; USDA Forest Service, Pacific Northwest Research Station; and Gifford Pinchot National Forest), Central Washington University, and the Marie Selby Botanical Gardens. Saul Lowitt assisted with experimental design.

\section{Literature Cited}

Basset, Y., V. Horlyck, and S.J. Wright. 2003. Studying forest canopies from above: the International Canopy Crane Network. Smithsonian Tropical Research Institute, and United Nations Environment Program, Panama. 
Braun, D.M., B. Runcheng, D.C. Shaw, and M. VanScoy. 2002. Folivory of vine maple in an old-growth Douglas-fir-western hemlock forest. Northwest Science 76:315-321.

Brubaker, L.B., and S.K. Greene. 1979. Differential effects of Douglas-fir tussock moth and western spruce budworm defoliation on radial growth of grand fir and Douglas-fir. Canadian Journal of Forest Research 9:95-105.

Carroll, G.C. 1991. Fungal associates of woody plants as insect antagonists in leaves and stems. Pages 253271 in P. Barbosa, V.A. Krischik, and C.G. Jones, editors, Microbial mediation of plant-herbivore interactions. Wiley, New York.

Coley, P.D. 1983. Herbivory and defensive characteristics of tree species in a lowland tropical forest. Ecological Monographs 53:209-233.

Edelstein, Z.R., and E.D. Ford. 2003. Branch and foliage morphological plasticity in old-growth Thuja plicata. Tree Physiology 23:649-662.

Field, C.B., AND J. KADUK. 2004. The carbon balance of an old-growth forest: building across approaches. Ecosystems 7:525-533.

Franklin, J.F., K. Cermack, Jr., W. Denison, A. McKee, C. Maser, J. Sedell, F. Swanson, and G. Juday. 1981. Ecological characteristics of old-growth Douglas-fir forests. General Technical Report PNW-118, USDA Forest Service, Pacific Northwest Research Station, Portland, OR.

Halaj, J., D.W. Ross, and A.R. Moldenke. 2000. Importance of habitat structure to the arthropod food-web in Douglas-fir canopies. Oikos 90:139-152.

Harmon, M.E., K. Bible, M.G. RYan, D.C. ShaW, H. Chen, J. KlopateK, AND X. Li. 2004. Production, respiration, and overall carbon balance in an old-growth Pseudotsuga-Tsuga forest ecosystem. Ecosystems 7: 498-512.

Landsberg, J., and C. Ohmart. 1989. Levels of insect defoliation in forests-patterns and concepts. Trends in Ecology and Evolution 4:96-100.

Lowman, M.D. 1984. An assessment of techniques for measuring herbivory: is rainforest defoliation more intense than we thought? Biotropica 16:264-268.

1985. Temporal and spatial variability in insect grazing of the canopies of five Australian rainforest tree species. Australian Journal of Ecology 10:7-24.

1995. Herbivory as a canopy process in rain forest trees. Pages 431-455 in M.D. Lowman and N.M. Nadkarni, editors, Forest canopies. Academic Press, San Diego, CA.

Lowman, M.D., AND H.B. Rinker, EDitors. 2004. Forest canopies. 2nd edition. Elsevier/Academic Press, San Diego, CA.

MCNAughton, S.J. 2001. Herbivory and trophic interactions. Pages 101-122 in J. Roy, B. Saugier, and H.A. Mooney, editors, Terrestrial global productivity. Academic Press, San Diego, CA.

Mitchell, A.W., K. Secoy, and T. Jackson. 2002. The global canopy handbook. Global Canopy Programme, Oxford, U.K

NilsSON, M.C., AND D.A. WARDLE. 2005. Understory vegetation as a forest ecosystem driver: evidence from the northern Swedish boreal forest. Frontiers in Ecology and the Environment 3:421-428.

Ozanne, C.M.P., D. Anhuf, S.L. Boulter, M. Keller, R.L. Kitching, C. Körner, F.C. Meinzer, et aL. 2003. Biodiversity meets the atmosphere: a global view of forest canopies. Science 301:183-186.

Parker, G.G. 1997. Canopy structure and light environment of an old-growth Douglas-fir / western hemlock forest. Northwest Science 71:261-270.

Paw U, K.T., M. Falk, T.H. Suchanek, S.L. Ustin, J. Chen, Y. PARK, W.E. Winner, ET AL. 2004. Carbon dioxide exchange between an old-growth forest and the atmosphere. Ecosystems 7:513-524.

Perry, D.A., and G.B. Pitman. 1983. Genetic and environmental influences in host resistance to herbivory: Douglas-fir and the western spruce budworm. Zeitschrift für Angewandte Entomologie 96:217-228.

Rinker, H.B., AND M.D. Lowman. 2004. Insect herbivory in tropical forests. Pages 359-386 in M.D. Lowman and H.B. Rinker, editors, Forest canopies. 2nd edition. Elsevier/Academic Press, San Diego, CA.

Schowalter, T.D. 1989. Canopy arthropod community structure and herbivory in old-growth and regenerating forests in western Oregon. Canadian Journal of Forest Research 19:318-322.

. 1995. Canopy arthropod communities in relation to forest age and alternative harvest practices in western Oregon. Forest Ecology and Management 78:115-125.

Schowalter, T.D., And L.M. Ganio. 1998. Vertical and seasonal variation in canopy arthropod communities in an old-growth conifer forest in southwestern Washington, USA. Bulletin of Entomological Research 88: 633-640.

Schowalter, T.D., W.W. Hargrove, and D.A. Crossley, JR. 1986. Herbivory in forested ecosystems. Annual Review of Entomology 31:177-196.

Shaw, D.C., J.F. Franklin, K. Bible, J. Klopatek, E. Freeman, S. Greene, and G.G. Parker. 2004. Ecological setting of the Wind River old-growth forest. Ecosystems 7:427-439.

Shaw, D.C., E.A. Freeman, and C. Flick. 2002. The vertical occurrence of small birds in an old-growth Douglas-fir-western hemlock forest stand. Northwest Science 76:322-334.

ShaW, D.C., and S. Greene. 2003. Wind River Canopy Crane Research Facility and Wind River Experimental Forest. Bulletin of the Ecological Society of America 83:115-121.

Thomas, S.C., And W.E. Winner. 2000. Leaf area index of an old-growth Douglas-fir forest estimated from direct structural measurements in the canopy. Canadian Journal of Forest Research 30:1922-1930.

USDA FOREST SERVICE. 2004. Forest insect and disease condition in the United States 2003. Forest Health Protection, USDA Forest Service, Washington DC.

Received 4 February 2005 Accepted 21 February 2006 